\title{
PENERAPAN E-COMMERCE UNTUK MENINGKATKAN PENJUALAN MENGGUNAKAN BUSINESS MODEL CANVAS STUDI KASUS: TOKO BAYU SPORTS
}

\author{
Febriza Putra Ramadhan ${ }^{1)}$, Goenawan Brotosaputro ${ }^{2)}$ \\ ${ }^{1}$ Sistem Informasi, Fakultas Teknologi Informasi, Universitas Budi Luhur \\ 1,2 Jl. Raya Ciledug, Petukangan Utara, Kebayoran Lama, Jakarta Selatan 12260 \\ E-mail : febrizaputra@gmail.com ${ }^{1)}$,goenawan.brotosaputro@budiluhur.ac.id²
}

\begin{abstract}
Abstrak
Persaingan bisnis menggunakan teknologi sudah sangat berkembang pesat salah satunya adalah internet yang sekarang juga sudah masuk ke dunia bisnis dimana dapat dijadikan sebagai strategi bisnis yang baik untuk kelangsungan bisnis mereka. Oleh karena itu para pelaku usaha dituntut untuk sudah mempunyai web ecommerce mereka masing-masing. E-Commerce adalah kegiatan pembelian maupun penjualan melalui jaringan internet mempertemukan perusahaan dan customer secara tidak langsung, melainkan bertemu melalui media internet. Metode Business Model Canvas (BMC) yang penulis gunakan untuk penilitian kali ini, bertujuan untuk menentukan strategi bisnis agar dapat dikelompokan sesuai elemen-elemen tertentu. Toko Bayu Sports adalah sebuah toko yang terletak di kota Tangerang Selatan ini menjual berbagai macam peralatan olahraga. Toko Bayu Sports masih kesulitan dalam mengelola data produk mereka dan dalam pembuatan laporan masih belum efisen karena masih dilakukan pembukuan secara manual serta lokasi toko yang masih jauh dari keramaian membuat toko bayu sports sulit untuk memasarkan produk-produk mereka. Untuk itu dengan adanya permasalahan yang terjadi seperti yang telah dijelaskan diatas, maka dibutuhkan sebuah sistem yang dapat mengakomodir permasalahan yaitu fitur transaksi secara online dan meminimalisir terjadinya kesalahan dalam pembuatan laporan. Maka berdasarkan hal tersebut dibutuhkan sebuah implementasi sistem berbasis ecommerce.
\end{abstract}

Kata kunci: e-commerce, peralatan olahraga, pemasaran

\section{PENDAHULUAN}

Toko Bayu Sports adalah sebuah toko yang terletak di kota Tangerang Selatan ini menjual berbagai macam peralatan olahraga. Berdasarkan hasil survey dan wawancara penulis dengan pemilik toko diketahui penjualan di toko tersebut masih dilakukan dengan cara konvensional dimana pembeli masih harus mendatangi toko untuk membeli produk yang mereka inginkan. Selain itu Toko Bayu Sports masih kesulitan dalam mengelola data produk mereka dan dalam pembuatan laporan masih belum efisen karena masih dilakukan pembukuan secara manual serta lokasi toko yang masih jauh dari keramaian membuat Toko Bayu Sports sulit untuk memasarkan produk-produk mereka.

"E-Commerce adalah kegiatan pembelian maupun penjualan melalui jaringan internet mempertemukan perusahaan dan customer secara tidak langsung, melainkan bertemu melalui media internet” [1].

Dengan di terapkannya sebuah webiste $e$ commerce pada toko bayu sports diharapkan dapat mengatasi masalah-masalah yang saat ini di alami toko bayu sports.

Penulis menggunakan metode Business Model Canvas (BMC) untuk membantu dalam menganalisa kebutuhan yang diperlukan untuk mengembangkan website e-commerce di toko bayu sports.

"Business Model Canvas adalah suatu tool yang dapat digunakan sebagai alat untuk melihat bagaimana model suatu usaha baik yang sedang dijalani maupun yang akan datang, tetapi tetap sesuai dengan elemen-elemen penting yang berhubungan dengan usahanya tersebut” [2].

"Sistem dapat di artikan sebagai suatu kumpulan jaringan kerja dengan prosedur tahapnya saling berhubungan satu sama lain, bersatu untuk melakukan suatu kegiatan yang dapat menyelesaikan tujuan tertentu dengan baik” [3].

"Sistem Informasi merupakan sebuah sistem yang dibertujuan untuk memberikan informasi bagi manusia terdari dari beberapa komponen untuk mecapai suatu tujuan tertentu” [4].

Adapun dalam penelitian ini, penulis meninjau studi sebelumnya untuk membantu penulis menyelesaikan penilitian ini, yaitu sebagai berikut:

Penelitian yang dilakukan oleh Sandy Kosasi dengan topik "Pembuatan Sistem E-commerce Produk Meubel Berbasis Komponen” [5]. Penelitian yang dilakukan oleh Abdi Pandu Kusuma dengan topik "Perancangan dan implementasi e-commerce untuk penjualan baju berbasis android "[6]. Penelitan yang dilakukan oleh Sutri Handayani 
dengan topik "Perancangan sistem informasi penjualan berbasis e-commerce studi kasus toko Kun Jakarta“ [1].

Adapun tujuan penelitian ini adalah untuk dapat meningkatkan penjualan yang terjadi di toko bayu sports serta memperluas pangsa pasar melalui interkasi antar pelanggan secara digital dan tidak terbatas dalam tempat maupun waktu dengan menitikberatkan kearah penyediaan alternatif antarmuka dalam media promosinya.

\section{METODE PENELITIAN}

\subsection{Metode Pengumpulan Data}

Penulis menggunakan metode pengumpulan data sebagai berikut :

a) Wawancara (Interview)

Penulis melakukan wawancara terhadap pemilik toko maupun customer guna mendapatkan data-data yang dapat dijadikan sebuah acuan dalam menyelesaikan masalah yang terjadi di toko bayu sports.

b) Pengamatan (Observasi)

Penulis melakukan observasi langsung ke toko bayu sports, agar dapat mengetahui dengan baik bagaimana proses penjualan dari awal sampai akhir pada toko bayu sports.

c) Analisa Dokumen

Penulis mengumpulkan dokumen-dokumen yang berkaitan dengan obyek penelitian yang nantinya akan dijadikan sebuah referensi dalam melakukan penelitian.

d) Studi Literatur

Dalam penelitian ini penulis melakukan studi literature menggunakan buku maupun jurnal penelitian sebelumnya yang berkaitan dengan topik yang sedang penulis buat. Adapun nantinya akan menjadi bahan acuan penulis untuk melakukan penilitian ini.

\subsection{Business Model Canvas}

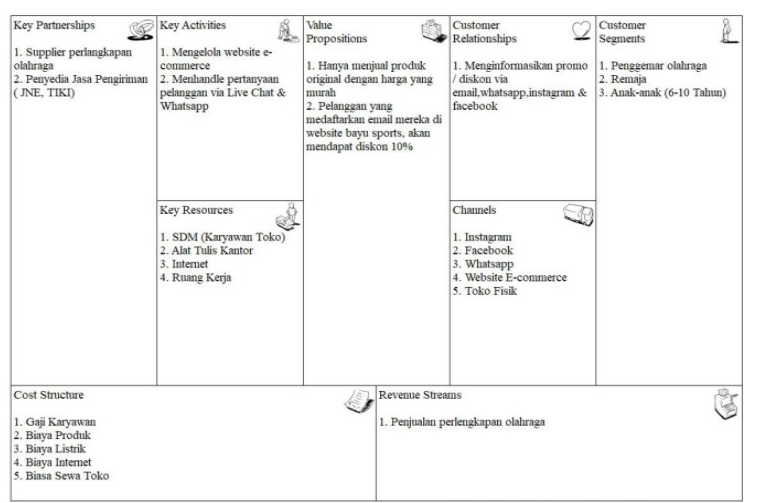

Gambar 1. Business Model Canvas Toko Bayu Sports
Penelitian ini menggunakan bantuan Business Model canvas untuk membantu peneliti untuk membuat sebuah model binis dalam bentuk kerangka kerja, Pada BMC yang penulis buat. Gambar 1 menjelaskan isi dari masing-masing elemen dari tabel Business Model Canvas.

\section{HASIL DAN PEMBAHASAN}

3.1. Proses Bisnis Usulan

\section{a. Proses Pendaftaran Pelanggan}

Sebelum pelanggan ingin membeli produk yang ada pada website Bayu Sports, pelanggan di haruskan melakukan registrasi akun di website Bayu Sports dengan mendaftarkan username, email \& password calon pelanggan. Dengan cara memilih menu my account yang tersedia pada website Bayu Sports. Lalu pelanggan mengisi form pendaftaran dengan lengkap, kemudian pelanggan klik tombol register

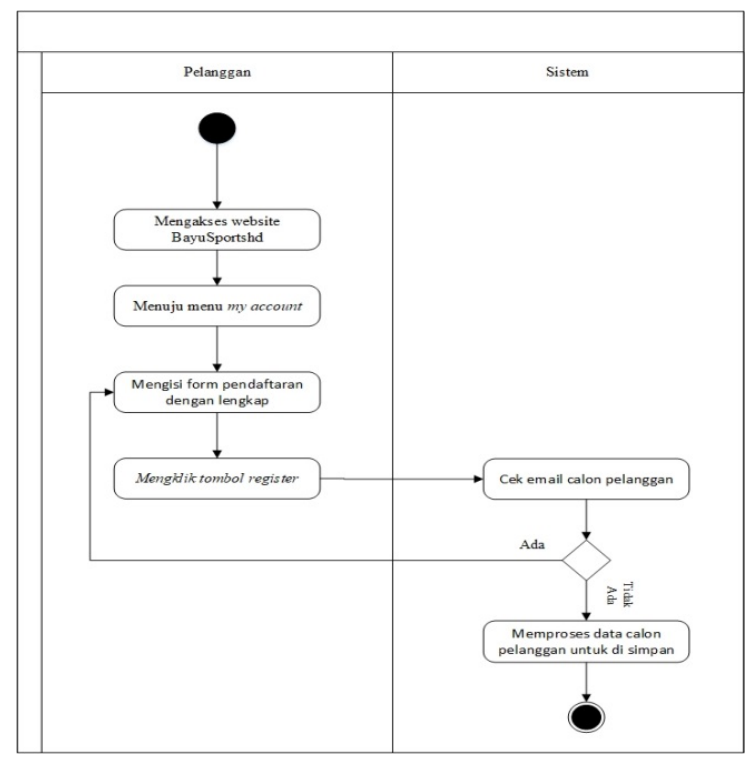

Gambar 2. Activity Diagram Proses Pendaftaran Pelanggan

Gambar 2 : Menjelaskan langkah-langkah dari proses pelanggan yang akan melakukan pendaftaran.

\section{b. Proses Pembayaran}

Pelanggan dapat melakukan pembayaran melalui transfer langsung ke ATM maupun mobile banking. 


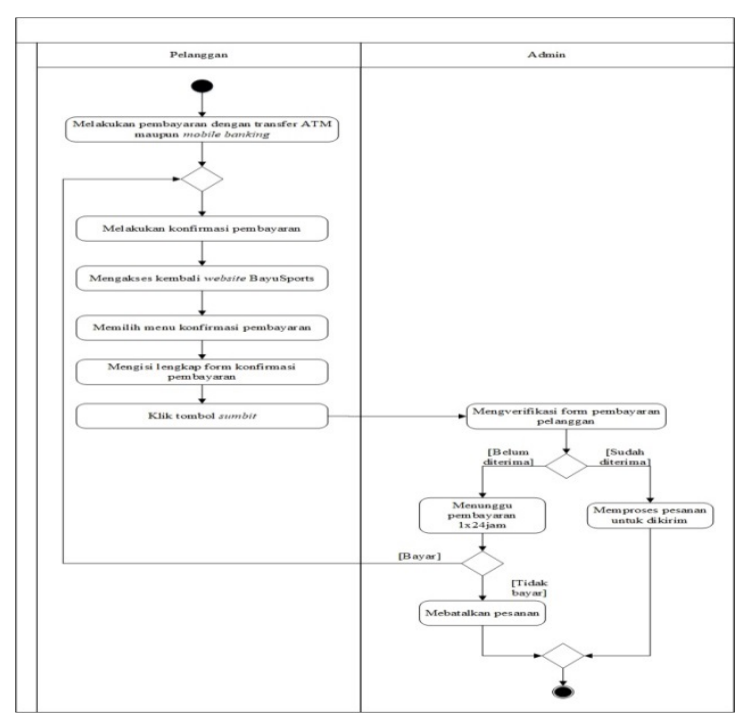

Gambar 3. Activity Diagram Proses Pembayaran

Gambar 3 : Menjelaskan langkah-langkah dari proses pelanggan yang akan melakukan pembayaran..

c. Proses Pembuatan Laporan

Admin mencetak laporan setiap akhir bulan maupun akhir tahun yang akan diberikan kepada pemilik toko.

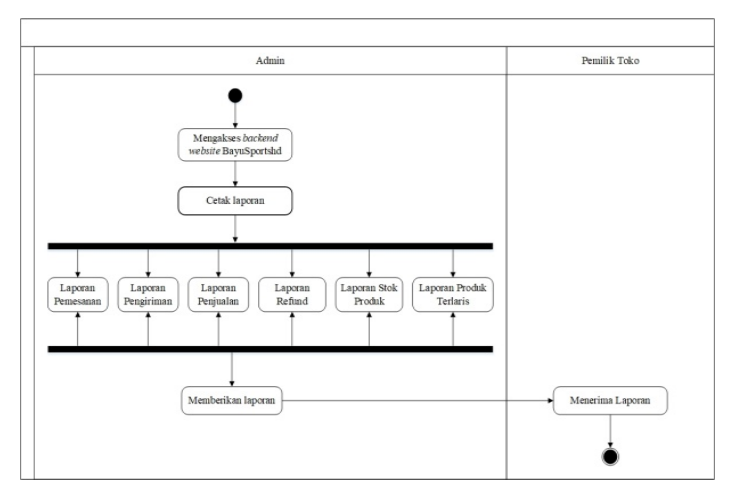

Gambar 4. Activity Diagram Pembuatan laporan

Gambar 4: Menjelaskan langkah-langkah proses admin dalam membuat sebuah laporan.

\subsection{Use Case Diagram}

a. Use Case Diagram Master Pelanggan

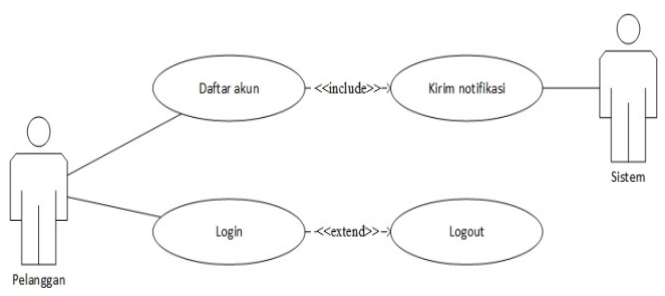

Gambar 5. Use Case Diagram Master Pelanggan
Gambar 5 : Menjelaskan use case master apa yang dapat di lakukan pelanggan

\section{b. Use Case Diagram Transaksi Pelanggan}

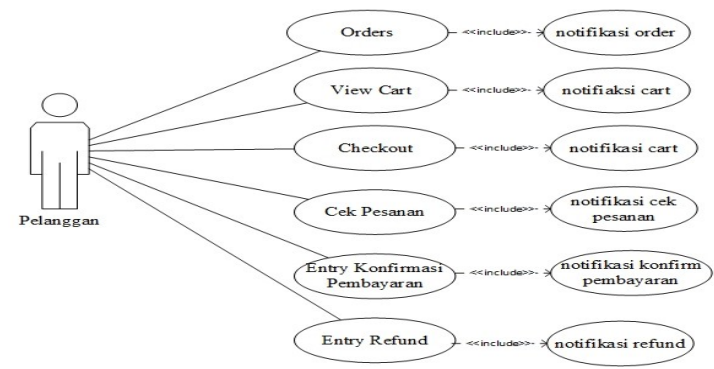

Gambar 6. Use Case Diagram Transaksi Pelanggan

Gambar 6 : Menjelaskan use case transkasi apa yang dapat di lakukan pelanggan.

\section{c. Use Case Transaksi Admin}



Gambar 7. Use Case Diagram Transaksi Admin

Gambar 7 : Menjelaskan use case transasksi apa yang dapat di lakukan admin.

\subsection{Class Diagram}

Berikut Class Diagram yang digunakan pada website e-commerce toko bayu sports:

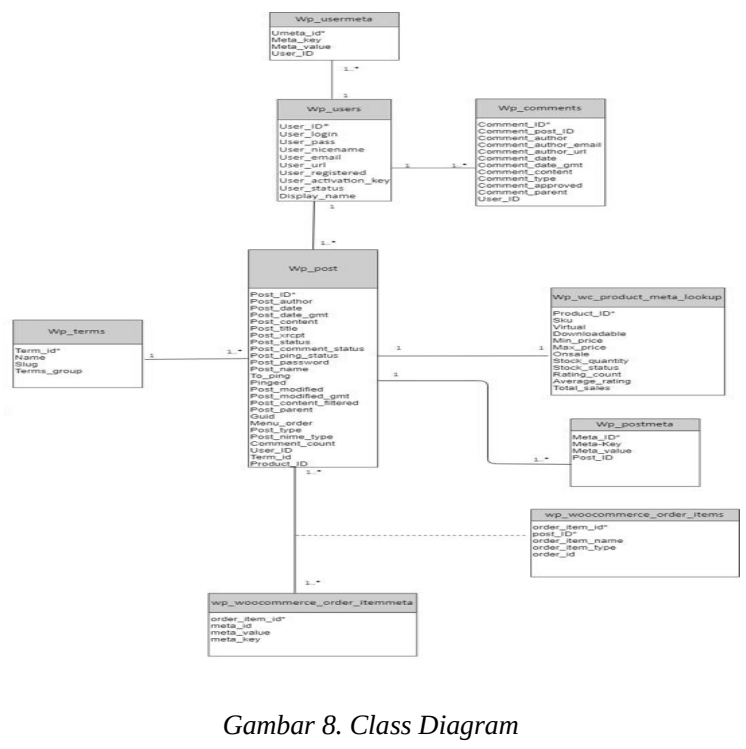

Gambar 8 : Menggambarkan sebuah bentuk class diagram yang digunakan dalam database sistem e-commerce toko bayu sports. 


\subsection{Struktur Tampilan Menu}

Berikut struktur tampilan menu yang ada pada website e-commerce toko bayu sports:

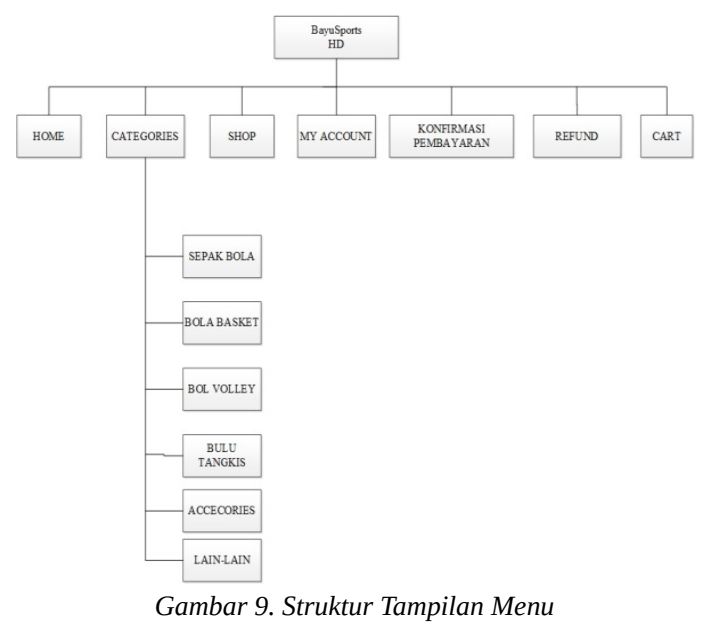

Gambar 9 : Menggambarkan seluruh tampilan menu yang terdapat dalam website toko bayu sports..

\subsection{Rancangan Layar}

a. Rancangan Layar Beranda

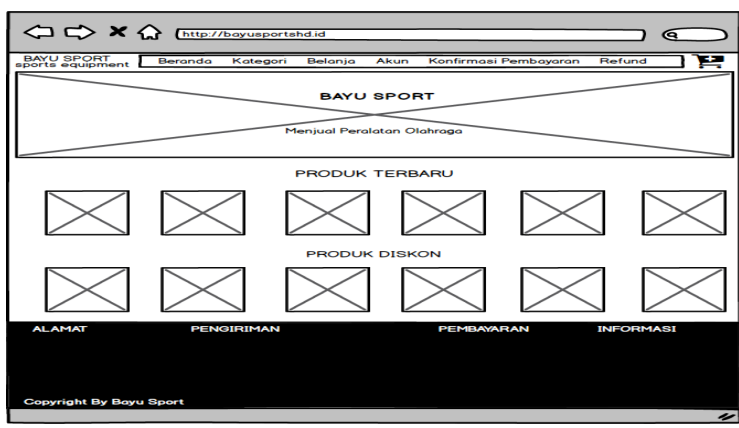

Gambar 10. Rancangan Layar Beranda

Gambar 10 : Menggambarkan rancangan layar yang terdapat dalam menu Beranda di toko bayu sports..

b. Rancangan Layar Konfirmasi Pembayaran

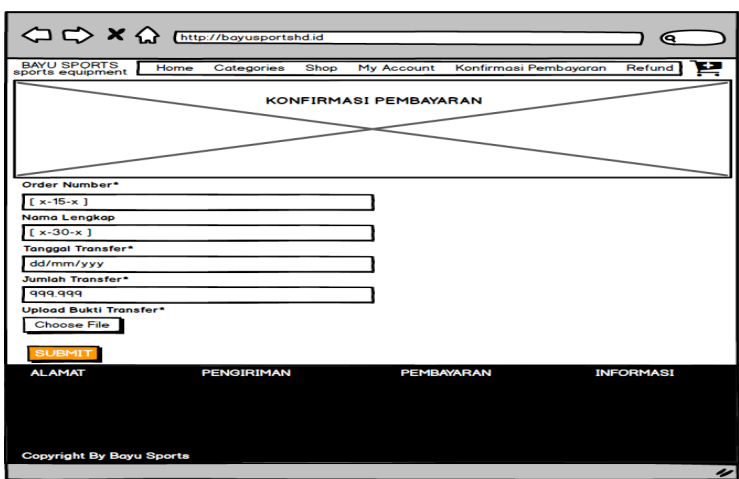

Gambar 11. Rancangan Layar Konfirmasi Pembayaran
Gambar 11 : Menggambarkan rancangan layar yang terdapat dalam menu Konfirmasi Pembayaran.

\section{c. Rancangan Layar Laporan Produk Terlaris}

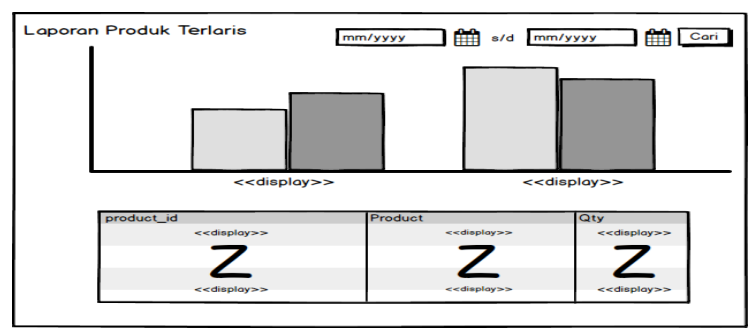

Gambar 12. Rancangan Layar Laporan Produk Terlaris

Gambar 12 : Menggambarkan rancangan layar yang terdapat dalam menu Laporan Produk Terlaris.

\subsection{IFML}

\section{a. IFML Tambah Produk}

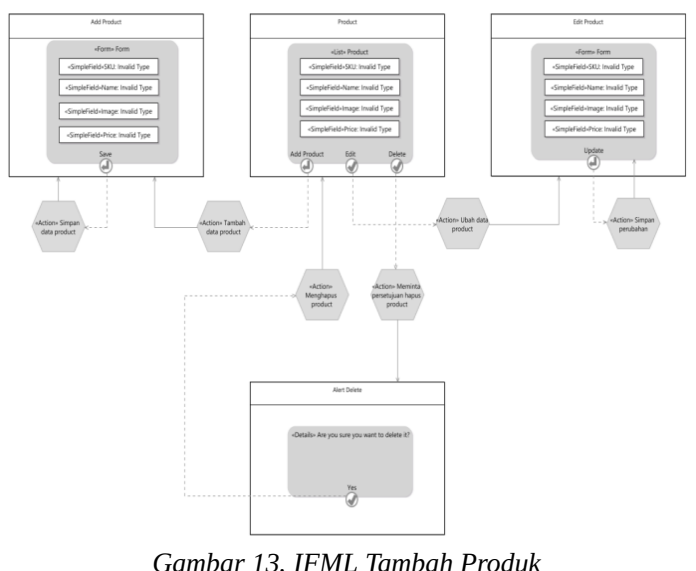

Gambar 13 : Menggambarkan interaksi layar bagaimana proses tambah produk di website..

\section{b. IFML Orders}

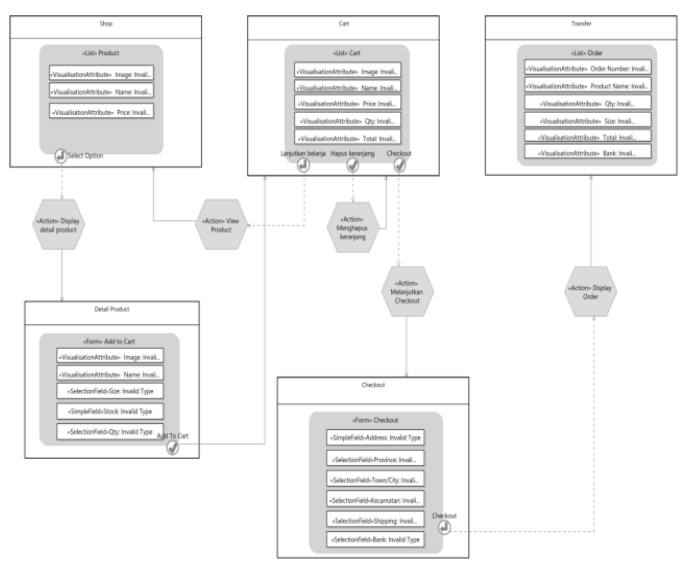

Gambar 14. IFML Orders 
Gambar 14 : Menggambarkan interaksi layar bagaimana proses pelanggan melakukan orders di website

\section{c. IFML Laporan Penjualan}

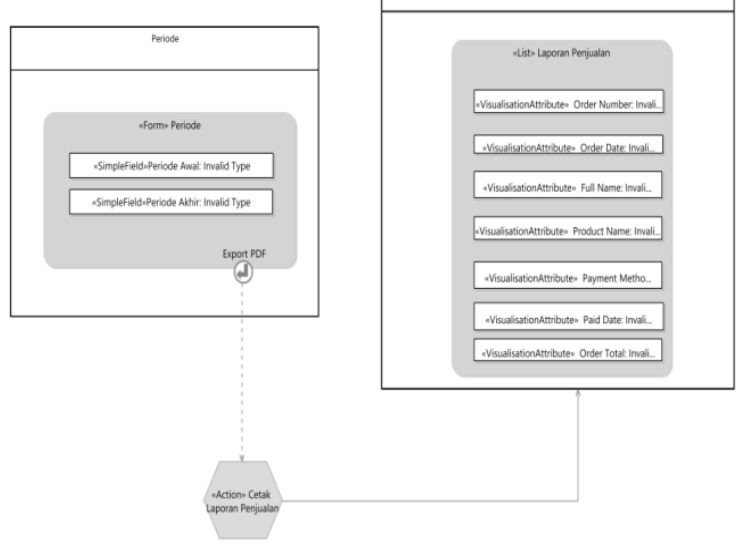

Gambar 15. IFML Laporan Penjualan

Gambar 15 : Menggambarkan alur bagaimana proses admin membuat sebuah laporan penjualan.

\subsection{System Sequence Diagram}

a. System Sequence Diagram Orders

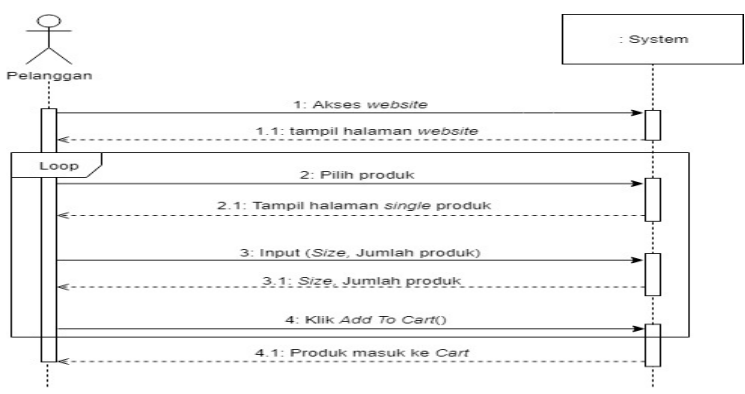

Gambar 16. System Sequence Diagram Orders

Gambar 16: Menggambarkan alur bagaimana proses pelanggan melakukan orders di website.

\section{b. System Sequence Diagram Konfirmasi Pembayaran}

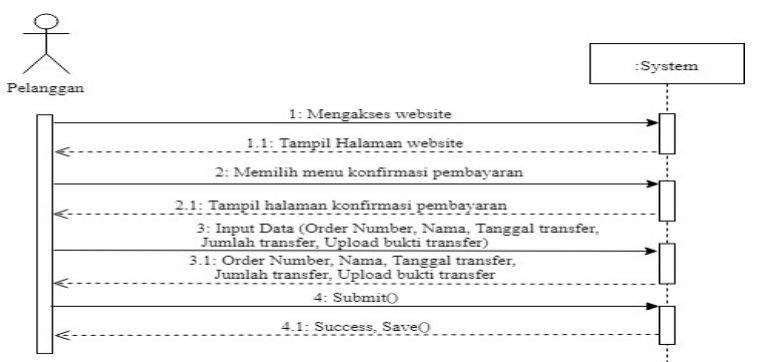

Gambar 17. System Sequence Diagram Confirmation Payments
Gambar 17 : Menggambarkan alur bagaimana proses pelanggan melakukan konfirmasi pembayaran di website.

\section{c. System Sequence Diagram Laporan Penjualan}

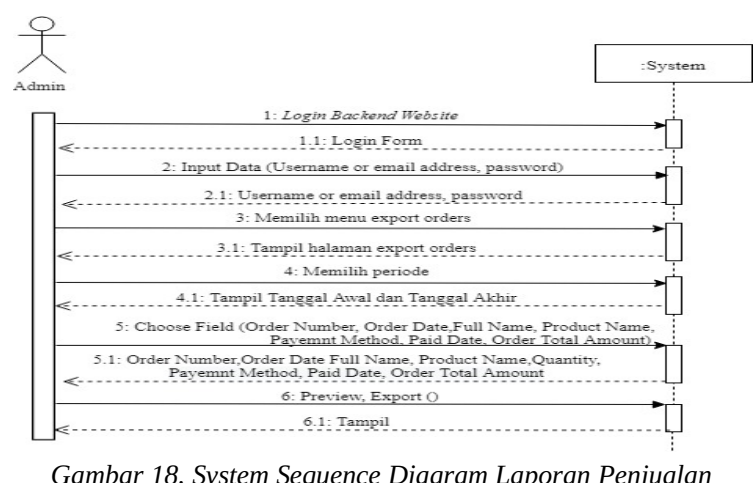

Gambar 18 : Menggambarkan alur bagaimana proses admin membuat laporan penjualan di website.

\section{KESIMPULAN}

Setelah mempelajari masalah yang dihadapi pada toko bayu sports, maka penulis dapat memberi kesimpulan sebagai berikut:

a. Dengan di implementasikannya sebuah fitur cart dan checkout orders pada sistem ecommerce dapat mempermudah pelanggan untuk melakukan transaksi tanpa harus datang ketoko.

b. Dengan adanya sebuah fitur stocks dan update stocks produk, maka memudahkan admin untuk mengelola data produk dan stok produk dengan baik.

c. Dengan diterapkannya strategi seo menggunakan back link dan share produk pada Instagram dan facebook pada bayu sport maka dapat menjangkau pelanggan dengan cakupan lebih luas lagi

d. Dengan adanya fitur penjualan, pemasanan, pengiriman secaran online pada website bayu sport maka penjualan akan lebih maksimal.

\section{DAFTAR PUSTAKA}

[1] Handayani, S. Perancangan Sistem Informasi Penjualan Berbasis E-Commerce Studi Kasus Toko Kun Jakarta, Jurnal Ilmiah, Hal.182. e-ISSN: 25487779. 2018.

[2] Nastiti, Faulinda. Analisis Kebutuhan Aplikasi Dengan Pemetaan pada Business Model Canvas, Seminar Nasional Teknologi Informasi dan Multimedia, Hal.155-160. ISSN: 2302-3805. 2014. 
[3] Sitohang, H. T. Sistem Informasi Pengagendaan Surat Berbasis Web Pada Pengadilan Tinggi Medan, Journal Of Informatic Pelita Nusantara, Hal. 6-9. eISSN 2541-3724. 2018.

[4] Wulandari, and Priyono. Implementasi E-commerce Pakaian pada Distro Bahana Shop, Jurnal TAM, Volume 3, Hal. 54-58. ISSN: 2579-4221. 2017.

[5] Kosasi. Pembuatan Sistem E-Commerce Produk Meubel Berbasis Komponen. IC-ITECHS , ISSN: 2087-1716, 2014.

[6] Kusuma, Prasetya. Perancangan E-Commerce Untuk Penjualan Baju Online Berbasis Android, Vol.11, No.2, p-ISSN 1978-5232. e-ISSN: 2527-337X. 2017. 